J Arid Land (2014) 6(1): 3-15

doi: $10.1007 / \mathrm{s} 40333-013-0193-8$

jal.xjegi.com; www.springer.com/40333

\title{
Index-based assessment of agricultural drought in a semi-arid region of Inner Mongolia, China
}

\author{
Rui LI $^{1 *}$, Atsushi TSUNEKAWA², Mitsuru TSUBO ${ }^{2}$ \\ ${ }^{1}$ United Graduate School of Agricultural Sciences, Koyama-Minami 4-101, Tottori University, Tottori 680-8553, Japan; \\ ${ }^{2}$ Arid Land Research Center, Tottori University, Hamasaka 1390, Tottori 680-0001, Japan
}

\begin{abstract}
Agricultural drought is a type of natural disaster that seriously impacts food security. Because the relationships among short-term rainfall, soil moisture, and crop growth are complex, accurate identification of a drought situation is difficult. In this study, using a conceptual model based on the relationship between water deficit and crop yield reduction, we evaluated the drought process in a typical rainfed agricultural region, Hailar county in Inner Mongolia autonomous region, China. To quantify drought, we used the precipitation-based Standardized Precipitation Index (SPI), the soil moisture-based Crop Moisture Index (CMI), as well as the Normalized Difference Vegetation Index (NDVI). Correlation analysis was conducted to examine the relationships between dekad-scale drought indices during the growing season (May-September) and final yield, according to data collection from 2000 to 2010. The results show that crop yield has positive relationships with CMI from mid-June to mid-July and with the NDVI anomaly throughout July, but no correlation with SPI. Further analysis of the relationship between the two drought indices shows that the NDVI anomaly responds to CMI with a lag of 1 dekad, particularly in July. To examine the feasibility of employing these indices for monitoring the drought process at a dekad time scale, a detailed drought assessment was carried out for selected drought years. The results confirm that the soil moisture-based vegetation indices in the late vegetative to early reproductive growth stages can be used to detect agricultural drought in the study area. Therefore, the framework of the conceptual model developed for drought monitoring can be employed to support drought mitigation in the rainfed agricultural region of Northern China.
\end{abstract}

Keywords: drought assessment; drought index; dekad time scale; rainfed agriculture

Citation: Rui LI, Atsushi TSUNEKAWA, Mitsuru TSUBO. 2014. Index-based assessment of agricultural drought in a semi-arid region of Inner Mongolia, China. Journal of Arid Land, 6(1): 3-15. doi: 10.1007/s40333-013-0193-8

Agricultural drought is the most frequent natural disaster and causes the heaviest crop damage in Inner Mongolia autonomous region of China (Shen, 2008), especially in regions where precipitation fluctuates greatly due to the influence of the East Asian monsoon, such as semi-arid zones. Accurate quantification of drought is difficult because its definition varies among climatic zones and it is context-dependent (Quiring, 2009). Following the definition of drought by the UNCCD (1994), in this study we consider agricultural drought to be a "naturally occurring phenomenon that exists when precipitation has been significantly below normal recorded levels, causing serious hydrological imbalances that adversely affect land resource production systems". For managing drought conditions, it is necessary to evaluate the status of the entire water cycle by looking at all available indicators to identify multiple aspects of the drought situation. Some assessment studies have focused on the essential characteristics of drought (Donald, 1994): intensity, duration, and spatial coverage. For example, Svoboda (2000) used drought monitoring categories to convert multiple indices into a common standardized form and then incorporated them into an objective single index

*Corresponding author: Rui LI (E-mail: lirui402@163.com) 
to evaluate drought intensity. Other assessments have evaluated the impact of drought based on these basic characteristics, including a study that assessed a map of drought conditions at a 2-week time scale using the Vegetation Drought Response Index (Brown et al., 2008) and studies based on multiple-year drought conditions (e.g. drought risk assessment by Heinrich et al., 1980 and Zhang et al., 2004; drought vulnerability assessment by Zarafshani et al., 2012). The onset of an agricultural drought may lag that of a meteorological drought, depending on the prior moisture status of the surface soil layers (Heim, 2002). Agricultural drought is a slow-onset "creeping phenomenon" (Tannehill, 1947), and there appears to be an inherent temporal relationship between shortage of rainfall and crop yield damage. In addition, according to the UNCCD (1994) definition, agricultural drought occurs when vegetation suffers from a water deficit. Therefore, for accurately identifying the features of agricultural drought in a specific region, it is necessary to examine the underlying drought process.

Numerous drought indices have been developed to simplify the identification of agricultural drought, and these indices can be divided into three groups. The first group is precipitation-based indices, such as precipitation anomaly and the Standardized Precipitation Index (SPI) (McKee et al., 1993, 1995). SPI is based on the assumption that precipitation over a period is a random variable distributed according to a gamma probability density function. The SPI is a typical meteorological drought index that considers only precipitation. It has been accepted by the World Meteorological Organization (WMO) as the reference index to characterize droughts. The second group is soil moisture-based indices, such as the Palmer Drought Severity Index (PDSI) (Palmer, 1965) and Crop Moisture Index (CMI) (Palmer, 1968). CMI is based on a subset of the calculations needed for PDSI, and it is designed to monitor short-term moisture conditions and crop stress across major crop-producing regions. Because CMI responds rapidly to changing conditions, it has advantages over PDSI in agricultural drought studies. The third group is vegetation-based indices, including the Ratio Vegetation Index (Jordan, 1969),
Normalized Difference Vegetation Index (NDVI) (Rouse et al., 1974), and Enhanced Vegetation Index (Huete et al., 2002). NDVI is calculated based on remote-sensing measurements of visible (red) and near-infrared (NIR) radiation. It is a measure of the greenness or vigor of vegetation. Among the vegetation indices, NDVI is the one most often used; it is an operational, globally-based vegetation index, partly due to its ratio properties, which enable the NDVI to cancel out a large proportion of noise in remote-sensing data caused by changing sun angles, topography, clouds or shadow, and atmospheric conditions (Huete et al., 1999). Stressed vegetation or vegetation with small leaf area has positive but low values of NDVI (Kogan, 1994). Therefore, NDVI is often used in research on vegetation dynamics (Zhou et al., 2009; Duan et al., 2011) and drought spatial monitoring (Kogan and Sullivan, 1993; Kogan, 1994; Kogan, 1997).

The relationship between moisture shortage and crop growth is the key link in the agricultural drought process. Previous studies have revealed that remotely sensed NDVI has a time-lag relationship with rainfall (Nicholson and Farrar, 1994; Wang et al., 2001; Ji and Peters, 2003). However, drought is a temporary feature in the context of climatic variability (WMO, 1975). Therefore, the NDVI anomaly (NDVIA) is a more accurate index of drought than is the NDVI. In addition to rainfall, however, meteorological factors such as temperature and wind speed also influence the water shortage of crops. Thus, it is more reasonable to assume that the NDVIA and water deficit reflect agricultural drought. Previous drought studies showed great variation in the relationship between moisture shortage and satellite-derived drought indices. For example, Bayarjargal et al. (2006) found no agreement between the spatial extent of satellite-derived drought indices and monthly PDSI. Quiring and Ganesh (2010) reported that monthly relative NDVI change index (vegetation condition index) is most strongly correlated with prolonged moisture stress, including 6-month SPI, 9-month SPI, and PDSI, and less sensitive to short-term precipitation deficiencies than to long-term ones (Quiring and Ganesh, 2010). Can NDVI change and in situ drought indices at shorter 
time scales provide detailed information indicating the vegetation response to water deficit? The temporal scale of dekad is often used in agricultural studies. In this study, we used short-term dekad vegetation variation to assess the ability of several indices to describe the agricultural drought process.

The overall goal of this study is to construct a framework to assess the agricultural drought process based on a conceptual model that synthesizes meteorological information, remote-sensing dynamic monitoring, and observational data. We then examined the relationships among indices and the temporal interaction of factors on a short time scale during the drought process. The specific objectives are to: (1) clarify trends of dekad-scale SPI, CMI, and NDVI during the crop growing period; (2) examine the relationships between drought indices and crop yield; (3) evaluate the temporal relationships among the drought indices, mainly focusing on water shortage accumulation and time lag; and (4) assess agricultural drought over a long-term period.

\section{Conceptual model of the agricultural drought process}

The agricultural drought process refers to the water balance within the weather-soil-crop agricultural production system. Crop growth can be divided into vegetative growth and reproductive growth stages. For a few crop types, yield is closely related to vegetative growth, such as crude fiber crops and leaf vegetables. For most crops, however, such as wheat, maize, and beans, the yield is closely related to reproductive growth. When drought occurs, leaves wither; thus, drought conditions affect these two categories of crops differently. For the former crop types, the yield will be closely correlated with vegetation damage. For the latter types, the damage of vegetation will influence yield via a reduction in the nutrition supply.

The key link during the drought process can be simplified as a temporal sequence of precipitation, soil moisture, vegetative growth, and yield. In rainfed agricultural regions, precipitation is the main water source, and yield is the final outcome of the drought process. During the generation of water stress, there is a time lag in the effect of soil moisture on vegetation vigor (Fig. 1). Following this framework, we used dekad-scale SPI, CMI, NDVIA, and yield as input for an assessment of the agricultural drought process.

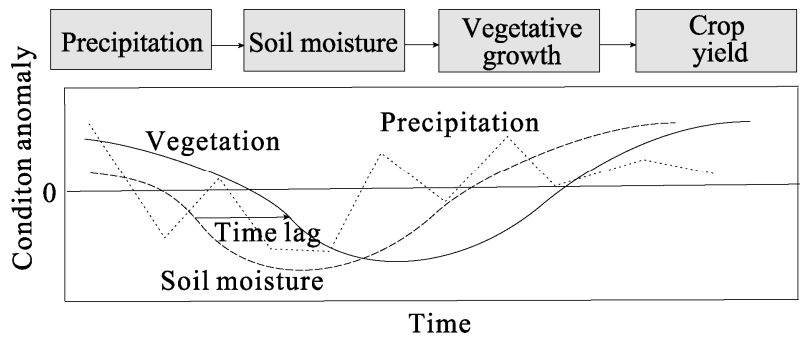

Fig. 1 Schematic diagram of the drought process during the crop growing period in a rainfed agricultural region

\section{Materials and methods}

\subsection{Study area}

The study area, Hailar county (total area $1,440 \mathrm{~km}^{2}$; Fig. 2), lies in the transitional zone between low mountains and the hilly region along the western slope of the Greater Khingan Mountains and Hulunbuir high plain in Inner Mongolia autonomous region, China. The elevation ranges from 603 to $777 \mathrm{~m}$ asl. Flat terrain is the county's main geomorphic feature. Chestnut soil is the main soil type, and the soil texture is loamy sand and loam (USDA classification, FAO soil map). Hailar county is in the semi-arid region (aridity index $=0.46$ ) of China. As an agriculture-pasture transitional zone, this region is strongly influenced by the East Asian summer monsoon and frequently suffers from extreme climatic conditions, such as limited precipitation and low temperature. According to measurements recorded at the Hailar weather station $\left(49^{\circ} 13^{\prime} \mathrm{N}, 119^{\circ} 45^{\prime} \mathrm{E}\right)$ of the Chinese Meteorological Administration, average annual precipitation (19712010 ) is $348 \mathrm{~mm}$. About two-thirds of the annual precipitation occurs from June to August, and rainfall increases significantly from late June to late August (i.e. the rainy season). In cold winters, the monthly mean temperature in January falls to $-26^{\circ} \mathrm{C}$. The whole county lies within the permafrost region, with 4-5 months of continuous snow cover each year ( $\mathrm{Li}$ and Mi, 1983; Jin et al., 2000); there is a short growing period (May to September).

Grassland and farmland are the two main land use 


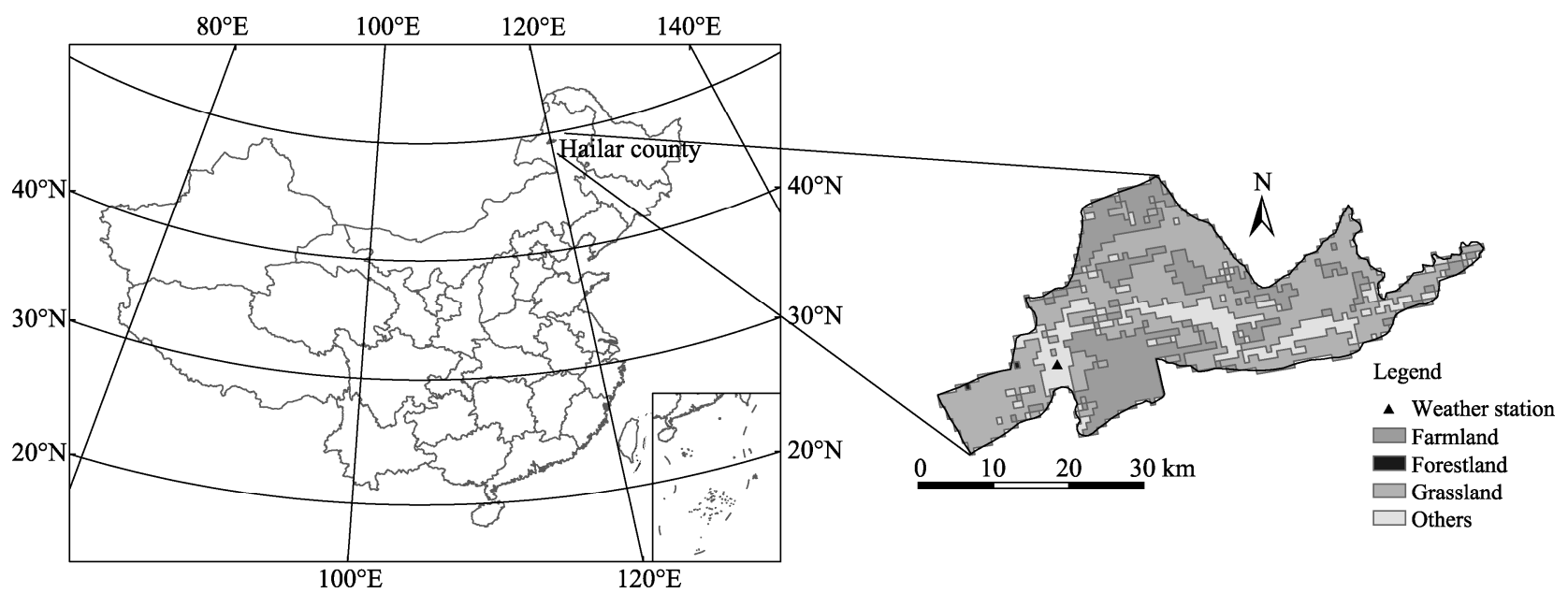

Fig. 2 The location of Hailar county in China and the distribution of land-use types (from 1-km grid land-use map of China in 2000)

types in Hailar country (Fig. 2). In 2009, 97\% of the farmland was unirrigated. Large areas of homogeneous cultivated plots exist in the county; these are suitable for monitoring crop growth based on moderate-resolution remote-sensing technology. In 1998, spring wheat (Triticum aestivum L.) was the main crop type, occupying $74 \%$ of the farmland. In 2010 , the proportion of spring wheat fell to $36 \%$, whereas those of barley (Hordeum vulgare L.) and potato (Solanum tuberosum L.) increased to $18 \%$ and $30 \%$, respectively; oil rape accounted for $10 \%$, vegetables accounted for $5 \%$, and soybeans, watermelon, and maize occupied the remaining $1 \%$. Thus, grain crops play an important role in the agricultural production of Hailar county.

\subsection{Data collection}

Daily meteorological data from the Hailar weather station (1951-2010), including precipitation, temperature, relative humidity, wind speed, and hours of sunshine, were downloaded from the China Meteorological Data Sharing Service System (http://cdc.cma. gov.cn/).

MODIS daily $500-\mathrm{m}$ products (MOD09GA h25v4) from May to September for the years 2000 to 2010 (for a total of 1,641 products) were downloaded from the U.S. Geological Survey's website (https://lpdaac. usgs.gov/). One product provides bands 1-7 in a daily gridded $\mathrm{L} 2 \mathrm{G}$ product that includes $500-\mathrm{m}$ reflectance values in the absence of atmospheric scattering or absorption.
A land-use map of China in $2000(1: 1,000,000$, 1-km grid, WESTDC) was downloaded from the Environmental and Ecological Science Data Center for West China, National Natural Science Foundation of China and Data-sharing Network of Earth System Science (http://westdc.westgis.ac.cn). The original dataset is a county-level land-cover dataset (vector format, scale: 1:100,000) from the Chinese Academy of Sciences. By the maximum area method, the datasets were combined and transferred to the final $1-\mathrm{km}$ raster product (Liu et al., 2001).

The water content available for farmland in Hailar county was calculated by an area-weighted method using the available water content records noted on a 1:1,000,000 scale soil map of China provided by the Chinese Academy of Sciences (downloaded from FAO Harmonized World Soil Database v 1.2, http://www.iiasa.ac.at/Research/LUC/External-World-soil-database/).

Crop planting area and yield data from 2000 to 2010 were collected from the Hailar Statistics Bureau. Although the meaning of crop yield varies across species, the most important aspect is the food energy. Yield energy analysis can measure total agricultural output of the farmland as well as the environmental contribution to crop production. The coefficients of the food energy obtained from the main crops in Hailar were taken from Shu et al. (2008): $16.3 \times 10^{6}$ $\mathrm{J} / \mathrm{kg}$ for wheat and barley grain, $20.9 \times 10^{6} \mathrm{~J} / \mathrm{kg}$ for soybean, $16.3 \times 10^{6} \mathrm{~J} / \mathrm{kg}$ for maize, $4.0 \times 10^{6} \mathrm{~J} / \mathrm{kg}$ for fresh potato, $26.3 \times 10^{6} \mathrm{~J} / \mathrm{kg}$ for oil rape, $2.5 \times 10^{6} \mathrm{~J} / \mathrm{kg}$ 
for vegetables, and $1.1 \times 10^{6} \mathrm{~J} / \mathrm{kg}$ for melon. Then, according to the sowing areas and production data for these eight types of crops during 2000-2010, the yield energy per unit area was estimated.

\subsection{Calculations of drought indices}

\subsubsection{SPI}

The SPI requires a long-term precipitation record to fit the gamma probability density function to the observed data (Zhou et al., 2001). Using the dekad data from 1951 to 2010, we calculated the dekad SPI with the method of McKee et al. (1993, 1995) for monthly data. The first dekad of the month is from day 1 to 10 , the second dekad is from day 11 to 20 , and the third dekad is from day 21 to the end of the month. By using the Normalized Root Mean Square Error (NRMSE) to test function fitness, we found that the cumulative probability of dekad precipitation fits the gamma cumulative distribution well (maximum NRMSE $<11 \%$ ). Therefore, dekad SPI can be used to reflect the amount of precipitation. To account for the antecedent rainfall of SPI in the effect on other factors, SPI was calculated with the simple averaging method using the following equation:

$$
\mathrm{SPI}_{n, s}=\frac{\sum_{k=s-n+1}^{n} \mathrm{SPI}_{k}}{n} .
$$

Where $n$ is the total number of the dekads considered, and $s$ is ascending time serial number of dekad SPI.

\subsubsection{CMI}

The CMI (Palmer, 1968) is based on a subset of the calculations required for the PDSI (Palmer, 1965). The CMI originated as a way to calculate the water balance using historic records of precipitation and temperature. Palmer introduced the concept climatically appropriate for existing conditions (CAFEC), which quantifies evapotranspiration, recharge, runoff, water loss, and precipitation. For the calculation of evapotranspiration, CAFEC assumes that soil moisture storage is handled by dividing the soil into two layers. For each dekad, when $E T_{o}<P, E T=E T_{o}$, where $E T$ is actual evapotranspiration, $E T_{o}$ is potential evapotranspiration, and $P$ is precipitation; if $E T_{o}>P$, then $E T$ is the sum of precipitation and water loss from the soil layers. The water losses from two layers are calculated as follows:

$$
\begin{gathered}
L s_{i}=\min \left[S s_{i-1},\left(E T_{o i}-P_{i}\right)\right], \\
L u_{i}=\left[\left(E T_{\mathrm{oi}}-P_{i}\right)-L s_{i}\right] S u_{i-1} / A W C, \quad L u_{i} \leq S u_{i-1} .
\end{gathered}
$$

Where $L s_{i}$ and $L u_{i}$ are the water loss from the surface and underlying soil for dekad $i$, respectively; $S s_{i-1}$ and $S u_{i-1}$ are the surface and underlying soil moisture for dekad $i-1$; and $A W C$ is the available water content.

Considering the short-term moisture supply and the moisture demand of the crop, CMI is the sum of evapotranspiration deficit and excessive moisture. The equations for these two aspects and CMI are as follows:

$$
\begin{gathered}
Y_{i}=0.67 Y_{i-1}+1.8 \frac{E T_{i}-\left(\alpha \times E T_{o i}\right)}{\sqrt{\alpha}}, \\
G_{i}=G_{i-1}-H_{i}+\left(M_{i} \times R_{i}\right)+R O_{i}, \\
C M I_{i}=Y_{i}+G_{i} .
\end{gathered}
$$

Where $Y_{i}$ is an index of evapotranspiration deficit for dekad $i$; $\alpha$ is a water balance coefficient; $G_{i}$ is an index of excessive moisture for dekad $i ; H_{i}$ is a "return-to-normal" factor; $M_{i}$ is the average percent of field capacity; $R_{i}$ is recharge; and $R O_{i}$ is runoff.

The $\mathrm{C}++$ package for computing CMI (scPDSI, version 2.0) was downloaded from http://greenleaf. unl.edu/downloads/scPDSI.zip. The original method for computing potential evapotranspiration $\left(E T_{o}\right)$ is based on the weekly Thornthwaite method (Thornthwaite, 1948). For obtaining the dekad estimation of $E T_{o}$, the Penman-Monteith FAO 56 model (Allen et al., 1998) was introduced to modify the program. The PMF-56 model is recommended as the sole method for determining $E T_{o}$, and it has been widely accepted as superior to other methods in China (Cai et al., 2007). Data of daily temperature, humidity, wind speed, and hours of sunshine were used to calculate daily $E T_{o}$ for estimating dekad $E T_{o}$. Then, dekad CMI values were obtained based on dekad- scale data from 1951 to 2010.

\subsubsection{NDVI anomaly}

In this study, we used MOD09GA bands 1 and 2, a band quality map, and a $1-\mathrm{km}$ reflectance state map from each daily MODIS product (h25v4). Bands 1-2 were first used for computing daily NDVI images according to Rouse et al. (1974). In the band quality 
map and resized 500-m reflectance state map, pixels with ideal quality and clear pixels were labeled and merged together. Then, the dekad synthesized NDVI as well as corresponding synthesis quality maps were produced based on daily images following the maximum-value composite procedure (Holben, 1986). Finally, with the help of the quality map, the noise was removed from the images. Due to a lack of images for NDVI from 15 June to 1 July 2001, there is no value for the third dekad of June 2001.

The farmland map of Hailar county was extracted from the land-use map of China. The farmland NDVI series were built using the MODIS dataset and a farmland mask. Because the area of Hailar county is small, the spatial differences of drought across the county were not considered here. Considering the farmland of the county as a whole, the NDVIA was calculated with the following equation:

$$
\mathrm{NDVIA}_{i, j}=\frac{\mathrm{NDVI}_{i, j}-\mathrm{NDVI}_{\text {ave }, j}}{\mathrm{NDVI}_{\mathrm{ave}, j}} \times 100
$$

Where $i$ is year, $j$ is dekad, and $\mathrm{NDVI}_{\mathrm{ave}, j}$ is the average value for the same dekad $j$ during 2000-2010. Because the county was considered to be one harvest region, the average value was computed using all the records in the same dekad.

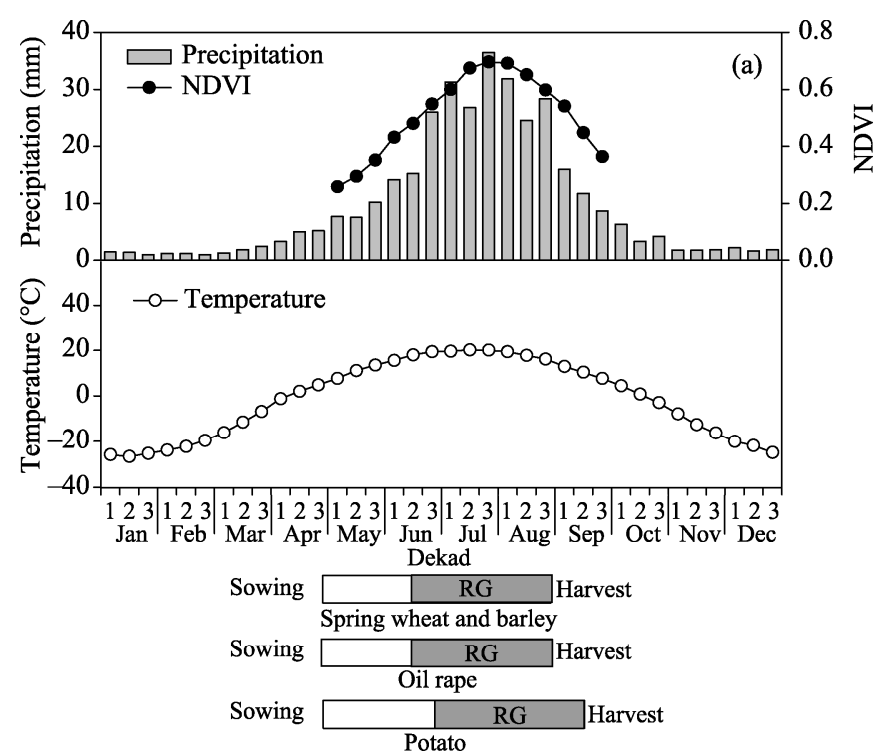

\subsection{Statistical analysis}

Using SPSS ver. 13.0 software (SPSS Inc., Chicago, IL, USA), we calculated $R^{2}$ and its significance level to identify the main period during which crop yield is sensitive to drought indices and the temporal relationships among the various indices during the drought process.

\section{Results}

\subsection{Seasonal trends of drought indices}

The average NDVI began to increase in early May and exceeded 0.3 in late May, when the average dekad temperature was higher than $0^{\circ} \mathrm{C}$; at this point, crop growth accelerated until the curve reached a peak in mid-July (Fig. 3a). After that, the NDVI decreased sharply until late September, when the average dekad temperature decreased again to $0^{\circ} \mathrm{C}$. With regard to local crop phenology, the sowing stage for spring wheat and barley in Hailer county is late April and harvest occurs in late August. The growing period of oil rape is from early May to late August, and that for potato is from early May to mid-September. Due to the short growing period in Hailar county, when the temperature peaks in July, most of the crops are just reaching the flowering stage. From 2000 to 2010, the

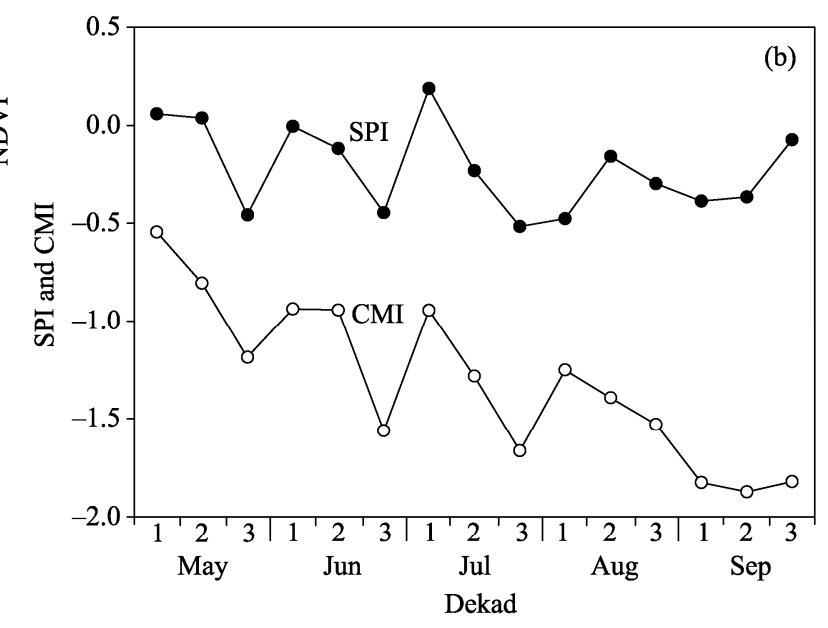

Fig. 3 The average dekad NDVI (a) and SPI and CMI (b) from 2000 to 2010 during the crop growing period. Panel (a) also shows the median temperature and average precipitation during 1951-2010 and crop phenology. Phenology information (sowing, harvest, and reproductive growth (RG) period) was obtained from Zhang et al. (1987), Wang and Zhao (2006), and interviews with staff of the Hailar Agricultural and Animal Husbandry Bureau. 1, 2, and 3 refer to the three dekads within each month. 
low values of SPI were in late May, late June, and from late July to early August (Fig. 3b). The shortage of rainfall frequently reduced the ability of the CMI value to return to normal, such that the CMI value tended to decrease during the growing period. These low-value periods in late June and late July span the elongation-heading and milky periods of spring wheat and barley, thus posing a high risk of yield reduction.

\subsection{Relationships of drought indices with crop yield}

The key period for dekad-scale CMI was from the second dekad in June to the second dekad in July (Table 1). The key period for NDVIA was from the first to the third dekad in July. There was clear seasonality in the relationship between crop yield and these indices. In addition, there were time lags between the sensitive period identified by CMI and those based on NDVIA. Our analyses revealed no clear sensitive dekad for SPI during June-July. However, with regard to cumulative average SPI values, there was a significant correlation with energy yield in May-June, May-July, May-August, and May-September, as was the case for CMI (Table 2). Thus, a longer period of precipitation accumulation has a greater effect on the energy yield than does a short period. For the SPI, the $R^{2}$ values were highest for May-June and then decreased. For the multi-dekad average of CMI and NDVIA, the $R^{2}$ values were highest for May-July and then decreased.

\subsection{Temporal relationships between drought in- dices}

The $R^{2}$ between CMI and average SPI was higher than that between average SPI and NDVIA. The strongest correlation for CMI was with the average SPI of four dekads (Fig. 4a). The strongest correlation for the NDVIA was with the average SPI of six dekads (Fig. $4 b)$. Thus, a precipitation shortage within a particular dekad does not directly influence the CMI and vegetation; rather, this occurs through a cumulative process.

When considering the correlation between CMI and the performance of the NDVIA from May to September over the 2000-2010 study period, the strongest correlation existed with a 1-dekad time lag (Fig. 5a). By considering the relationship between these indices for each month separately, the maximum $R^{2}$ ranged from 0.319 (September) to 0.619 (July). The highest correlations between these indices occurred in July and showed a 1-dekad time lag (Fig. 5b).

\subsection{Drought assessment}

During 2000-2010, crop yield was heavily reduced in 2001, 2003, 2004 and 2007. For each of these drought years, as assessed by SPI, CMI, and NDVIA, there was a time lag between CMI and NDVIA (Fig. 6). The year 2003 had the most serious yield reduction, with the yields of spring wheat, oil rape, and potato all being lowest during the 11 years. The CMI value in the first dekad of May was less than -2 , indicating that

Table 1 The coefficient of determination $\left(R^{2}\right)$ between dekad-scale indices and crop energy yield anomaly in Hailar county during 2000-2010

\begin{tabular}{|c|c|c|c|c|c|c|c|c|c|c|c|c|c|c|c|}
\hline \multirow{2}{*}{ Index } & \multicolumn{3}{|c|}{ May } & \multicolumn{3}{|c|}{ June } & \multicolumn{3}{|c|}{ July } & \multicolumn{3}{|c|}{ August } & \multicolumn{3}{|c|}{ September } \\
\hline & 1 & 2 & 3 & 1 & 2 & 3 & 1 & 2 & 3 & 1 & 2 & 3 & 1 & 2 & 3 \\
\hline$\overline{\text { SPI }}$ & 0.006 & 0.039 & 0.058 & 0.038 & 0.217 & 0.327 & 0.136 & 0.019 & 0.014 & $0.455^{*}$ & 0.051 & 0.023 & 0.008 & 0.022 & 0.007 \\
\hline CMI & 0.002 & 0.003 & 0.035 & 0.139 & $0.814^{* *}$ & $0.630^{* *}$ & $0.526^{*}$ & $0.638^{* *}$ & 0.160 & 0.012 & 0.027 & 0.081 & $0.602^{* *}$ & 0.002 & 0.003 \\
\hline NDVIA & 0.204 & 0.240 & 0.000 & 0.097 & 0.087 & 0.249 & $0.723^{* *}$ & $0.665^{* *}$ & $0.647^{* *}$ & 0.176 & 0.042 & 0.157 & 0.244 & 0.072 & 0.029 \\
\hline
\end{tabular}

Note: ${ }^{*}$ and ${ }^{* *}$ represent statistical significance at the 0.05 level and the 0.01 level, respectively. $n=11$. For NDVIA, $n=10$ in the $3^{\text {rd }}$ dekad of June.

Table 2 The coefficient of determination $\left(R^{2}\right)$ between multi-dekad average values of indices and crop energy yield anomaly in Hailar county during 2000-2010

\begin{tabular}{lccccc}
\hline Index & May & May-June & May-July & May-August & May-September \\
\hline SPI & 0.023 & $0.587^{* *}$ & $0.388^{*}$ & $0.588^{* *}$ & $0.538^{*}$ \\
CMI & 0.006 & $0.523^{*}$ & $0.638^{*}$ & $0.623^{*}$ & $0.602^{* *}$ \\
NDVIA & 0.073 & 0.136 & $0.403^{*}$ & 0.356 & 0.205 \\
\hline
\end{tabular}

Note: ${ }^{*}$ and ${ }^{* *}$ represent statistical significance at the 0.05 level and the 0.01 level, respectively. $n=11$. 

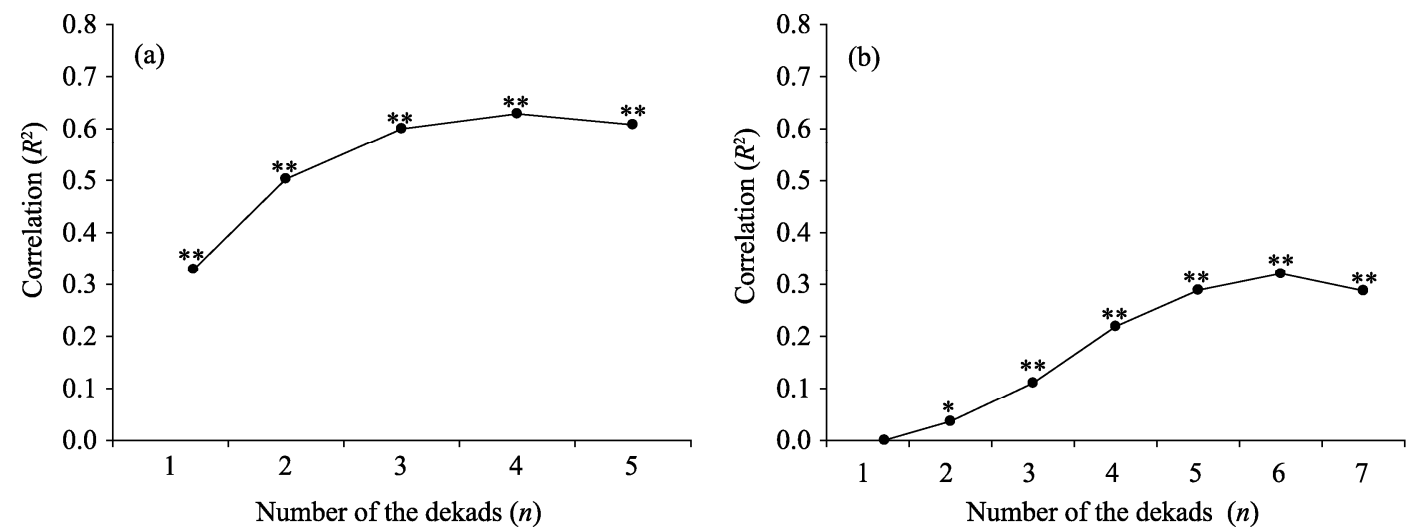

Fig. 4 The coefficient of determination $\left(R^{2}\right)$ between multi-dekad SPI and CMI (a; $\left.n=165\right)$ and SPI and NDVIA (b; $\left.n=164\right)$ during May to September from 2000 to 2010 in Hailar county. The $x$-axes denote the number of dekads for SPI, with, for example, 2 indicating 2 dekads (1 antecedent dekad). * and ** represent statistical significance at the 0.05 level and the 0.01 level, respectively.
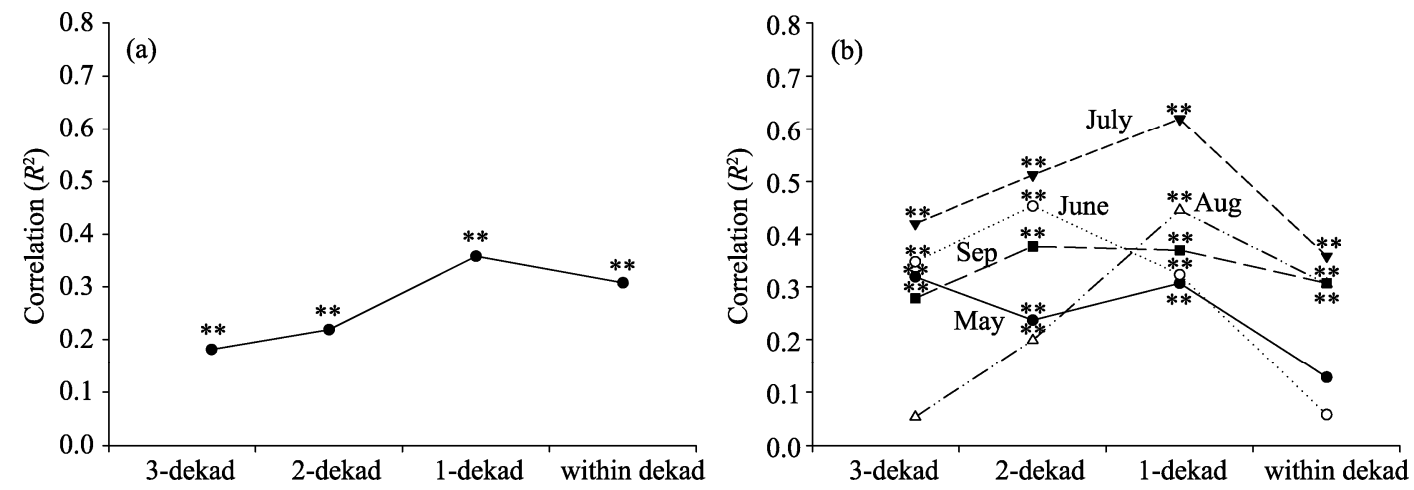

Fig. 5 The coefficient of determination $\left(R^{2}\right)$ between CMI and NDVIA over the entire growing period (a; $\left.n=164\right)$ and in individual months of May-September (b; $n=33$ ) from 2000 to 2010 in Hailar county. The $x$-axes denote the time lag between the indices. In panel (b), $n=32$ for June. * and $* *$ represent statistical significance at the 0.05 level and the 0.01 level, respectively.

there was a lack of soil moisture before the growing season. After sowing, from early May to early July, the SPI values were continuously less than 0 . This long-term precipitation shortage caused a gradual decrease in CMI until mid-July, when the soil moisture began to recover. Although the SPI value seemed to return to normal in early June, this short-term precipitation neither changed the decreasing trend in CMI nor mitigated the drought conditions. The shortage of water ultimately caused a continuous decrease in the NDVIA. Because there was a 1-dekad time lag between CMI and NDVIA, the vegetation recovery began in late July. SPI was close to or higher than 0 from mid-July to early August, so the CMI value increased and returned to normal. The recovery of soil moisture also prompted the recovery of NDVI. The vegetation condition returned to normal in mid-August. However, this recovery period occurred too late in the growing season. Therefore, the yield was heavily reduced due to this spring and summer drought.

In contrast, the period of serious drought in 2007 was in summer and autumn. The precipitation in mid and late May provided good moisture conditions during the crop seeding period. The NDVIA showed that the growth condition was even better than normal. However, there was a series of dekads after mid-June when precipitation was lower than normal, particularly the dekad in late July, with only $0.4-\mathrm{mm}$ precipitation. CMI showed that water stress rose to the most serious point in late July. Due to this water stress, NDVIA decreased sharply and fell to the lowest point in mid-August. Although the precipitation in August returned to normal, the NDVIA did not recover to normal levels until mid-September. By that point the crops had already passed through the flowering stage, and the yield suffered great damage. 

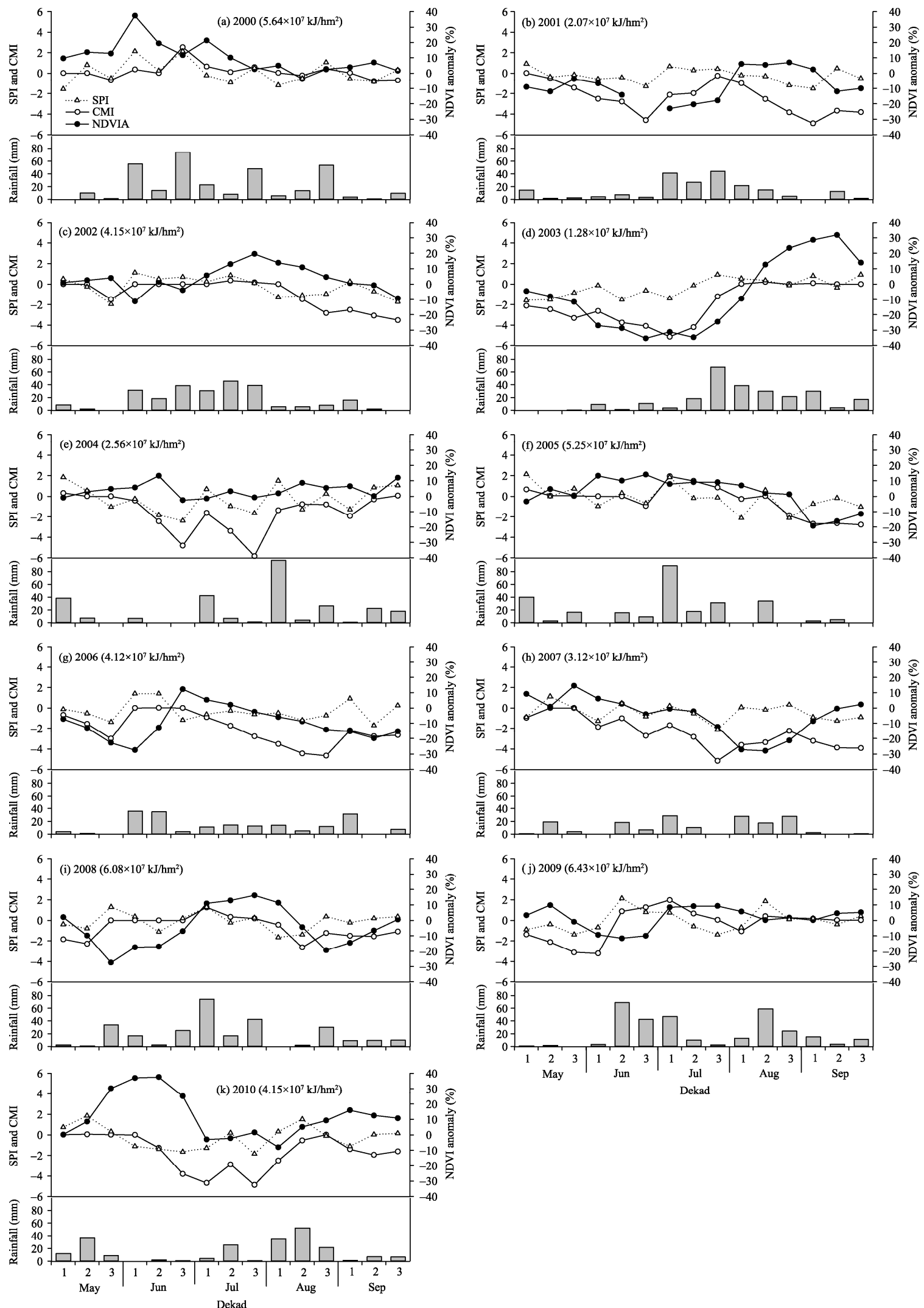

Fig. 6 Drought process from 2000 to 2010 in Hailar county. Values in parentheses behind the years represent total crop yield energy. 
In 2001, although precipitation conditions improved in early May, the continuing low precipitation from mid-May to late June decreased the CMI. NDVIA started to decrease due to water stress in early June. In July, the precipitation returned to normal, and CMI slowly returned to normal in late July. NDVIA recovered to 0 in early August. Precipitation began a continuous decline in late August, and NDVIA rapidly declined in mid-September due to water shortage.

In 2004, the precipitation continually decreased beginning in mid-June, and the NDVIA began to decline in late June. Because the precipitation in early July was higher than normal, CMI recovered quickly. NDVIA recovered to nearly $-10 \%$ in mid-July. After that, CMI started to decrease in mid-July, and NDVIA deceased in late July. The precipitation in early August caused a sharp increase in CMI, and subsequently NDVIA increased in mid-August. CMI decreased in early September, and NDVIA decreased in midSeptember. Following several dry spells, there was an 85.5-mm precipitation event on 3 August 2004. The growth period was nearly at the milky ripe stage for wheat and barley, and the stems were fragile. It is possible that the heavy rainfall also caused early falling of the wheat ear, thus lowering the yield.

\section{Discussion}

\subsection{Recent trends of climate and agricultural drought}

The frequency of extreme drought in northeastern China has obviously been increasing since the 1980s, which is closely related to decreased precipitation and increased temperature (Ma and Fu, 2006). Since 2000, this dry and warm trend has been significant in Hailar county (Fig. 3b). In addition, the decrease in precipitation influenced the moisture balance and increased water stress on crops. Because the water deficit occurs during the key reproductive growth period (flowering time) of crops, the energy yield has suffered greatly from the water deficit. These findings suggest that in semi-arid regions such as Hailar county, the drying and warming climate trends that have occurred during the growing season over the past decade mean that meteorological drought has easily transformed into agricultural drought.

\subsection{Critical growth stages related to crop yield reduction}

The majority of the crops in Hailar county are grains, such as spring wheat and barley, the yield of which is closely related to reproductive growth. Our results show that vegetation vigor as measured by NDVI best reflects yield energy in July (Table 1). Deng et al. (2011) studied spring wheat in northern Hailar county and Chen Barag Banner (adjacent to Hailar county) by comparing the actual yield and NDVI in a 30-m image taken on 29 July 2009 by the Chinese HJJZ satellite; they found an extremely significant correlation between this index and yield. Likewise, a study conducted in the Canadian prairies showed that MODIS-NDVI from the third dekad of June through the third dekad of July could well predict the yields of barley, canola, field peas, and spring wheat in the sub-humid zone (Mkhabela et al., 2011). The Canadian prairies and Hailar county share a similar crop planting structure and growing season (May-August).

Research on crop physiology has shown that for cereal crops, the uppermost leaves (i.e. the flag leaves) are an important source of carbohydrate production. The flag leaves, which emerge during the tillering stage, make up approximately $75 \%$ of the effective leaf area that contributes to grain filling (Miller, 1999). The characteristics of flag leaves reflect photosynthetic activities and are considered to be some of the greatest components in determining grain yield potential (Hirota et al., 1990). In Hailar county, the grain-filling stage for spring wheat is in mid-July. Thus, it is possible that vegetation indices in July reflect the growth condition of flag leaves and thereby effectively monitor yield damage.

The key water stress period identified by dekadscale CMI can be validated by research on crop water requirements. According to experiments on spring wheat in Northern China and actual measurements of evapotranspiration and the soil water balance equation, water consumption of spring wheat reached a peak during the jointing to milky period, which accounted for $47.5 \%$ of the total water consumption ( $\mathrm{Li}$ et al., 2003). The jointing to milky period for spring wheat 
in Hailar county is from late June to late July. Perhaps the unbalanced state between the water supply and water consumption by spring wheat during this period is what allowed CMI in mid- to late June to provide the best forecast of yield. The key period identified by CMI is a little earlier than that identified by NDVIA (Table 1). The significant time lag between CMI and NDVIA in July (Fig. 5) suggests that the influence of dekad-level water stress on the ability of flag leaves to produce carbohydrates around the grain-filling period (mid-July) is a substantial agricultural drought process that decreases yield of spring wheat in Hailar county.

\subsection{Time lags between water deficit and NDVI}

SPI was originally calculated at a monthly scale (McKee et al., 1993). Because 1-month SPI reflects relatively short-term conditions, its application relates closely with short-term soil moisture and crop stress, especially during the growing season. In this study, the cumulative period from SPI to CMI was about 4 dekads (Fig. 4a). Our findings show that the dekadscale CMI can bridge the gap between short-term vegetation change and water deficit as depicted by an in situ meteorological dataset. In May, June, and September, the time lag between CMI and NDVI was longer than that in July and August, during the growing period (Fig. 5). The measurement of soil moisture at Ewenki, Ergun, and Zhalantun experiment stations (near Hailar county) showed that in spring, after snow melt, there is a period of significant soil moisture loss from early April to early June due to strong wind (Wang and Zhao, 2006). CMI may perform poorly in depicting the soil moisture balance influenced by snow melt and strong wind in spring.

The average time lag between CMI and NDVI was 1 dekad during the growing period, and our findings suggest that CMI could be used to track the change of a dekad-scale crop NDVI in similar rainfed agricultural regions. In a previous study, Zipporah (2011) investigated the temporal aspects of drought in Africa based on NDVI and Owe's AMSR-E soil moisture dataset, using correlation analysis and a distributed lag model (Dominic et al., 2002). The results show that a 10-day lag between NDVI and soil moisture was the dominant pattern in grassland, cropland, and shrubland. Gu et al. (2008) evaluated the temporal relationship between NDVI and soil moisture data at 10 homogeneous grassland sites; at 7 of the sites there was a 1 - to 2 -week time lag in the NDVI response to soil moisture variation in the $5-$ and $25-\mathrm{cm}$ soil layers. Thus, our finding that the response time of crop vegetation to soil moisture is 1 dekad is comparable with the results of previous studies.

\subsection{Feasibility of using SPI, CMI, and NDVI for monitoring agricultural drought}

Our detailed assessment of the agricultural droughts in 2001, 2003, 2004 and 2007 shows that SPI, CMI, and NDVI can depict the processes underlying a serious drought at a dekad time scale during the growing season. Based on these three indices, it is possible to judge the likelihood of drought development and to assess the possible yield damage. Dekad-scale SPI can be regarded as the earliest indicator of drought impact on crops. The relationship between CMI and NDVIA displays a significant time lag. In this study, the dekad synthesized NDVI values were produced using the maximum-value composite method (Holben, 1986) to reduce noise. Therefore, although dekad-scale NDVI is not a direct measure of crop growth, the results of this study suggest that NDVI provides sufficient information to reflect the response of crops to drought at the dekad time scale.

\section{Conclusion}

Our findings indicate that the agricultural drought assessment model is suitable for regions where crop yield is closely related to the reproductive growth stage. In our assessment based on the proposed model, we were able to track the drought process in Hailar county: we found that meteorological drought during 2000-2010 was easily transformed into agricultural drought. In this region where grain crops, including spring wheat and barley, are the main crop types, soil moisture-based vegetation indices during the late vegetative to early reproductive growth stages (CMI in June and NDVIA in July, respectively) could be used to detect agricultural drought. The most frequent average time lag between CMI and NDVI was 1 dekad, especially in July. The results of this 11-year 
assessment at the dekad time scale in Hailar county fit the conceptual model of the agricultural drought process well. Our findings suggest that when synthesizing multiple indices to identify drought features at a short time scale, the underlying drought process needs to be considered. Future research of the drought process should consider the calibration of fixed parameters for CMI using cases of drought lasting for longer time periods, the effects of snow melt and strong wind on soil moisture in spring, the role of human activity, and the influence of other disasters on yield, such as insect attack. In regions with a drying and warming climate trend, such as Hailar county, longer-term or more sustainable measures, such as adjusting the cultivation calendar or crop planting structure, may be necessary to prevent damage from agricultural drought in the future.

\section{Acknowledgements}

This research was supported by the Global Center of Excellence Project for Dryland Science of the Ministry of Education, Culture, Sports, Science and Technology of Japan. We are grateful to Hailar Agricultural and Animal Husbandry Bureau for the assistance during interview.

\section{References}

Allen R G, Pereira L S, Raes D, et al. 1998. Crop evapotranspiration: guidelines for computing crop water requirements. Rome, Italy: FAO Irrigation and Drainage Paper, 56: 23-28, 106.

Bayarjargal Y, Karnieli A, Bayasgalan M, et al. 2006. A comparative study of NOAA-AVHRR derived drought indices using change vector analysis. Remote Sensing Environment, 105(1): 9-22.

Brown, J F, Wardlow B D, Tadesse T, et al. 2008. The Vegetation Drought Response Index (VegDRI): a new integrated approach for monitoring drought stress in vegetation. GIScience and Remote Sensing, 45(1): 16-46.

Cai J, Liu Y, Lei T, et al. 2007. Estimating reference evapotranspiration with the FAO Penman-Monteith equation using daily weather forecast messages. Agricultural and Forest Meteorology, 145: 22-35.

Deng K M, Sun J L, Chen P F, et al. 2011. Estimation of spring wheat yield by remote sensing information from China's environmental disaster mitigation satellite-taking Chen Barag Banner of Inner Mongolia as an example. Journal of Natural Resources, 26(11): 1942-1952.

Dominic S, Derric R. 2002. Schaum's Outline of Theory and Problems of Statistics and Econometrics. New York: McGraw-Hill Companies, Inc.
Donald A W. 1994. Preparing for Drought: A Guidebook for Developing Countries. Pennsylvania: Diane Books Publishing Company, 7-8.

Duan H, Yan C, Tsunekwawa A, et al. 2011. Assessing vegetation dynamics in the Three-North Shelter Forest region of China using AVHRR NDVI data. Environmental Earth Sciences, 64(4): 1011-1020.

Gu Y X, Hunt E, Wardlow B, et al. 2008. Evaluation of MODIS NDVI and NDWI for vegetation drought monitoring using Oklahoma Mesonet soil moisture data. Geophysical Research Letters, 35: L22401.

Heim R R. 2002. A review of twentieth century drought indices used in the United States. Bulletin of the American Meteorological Society, 83(8): 1149-1165.

Heinrich H W, Petersen D, Roos N. 1980. Industrial Accident Prevention A Safety Management Approach. New York: McGraw-Hill, 468.

Hirota O, Oka M, Takeda T. 1990. Sink activity estimation by sink size and dry matter increase during the ripening stage of barley (Hordeum vulgare) and rice (Oryza sativa). Annals of Botany, 65: 349-354.

Holben B N. 1986. Characteristics of maximum-value composite images for temporal AVHRR data. International Journal of Remote Sensing, 7: 1435-1445.

Huete A, Justice C, van Leeuwen W. 1999. MODIS Vegetation Index (MOD13) Algorithm Theoretical Basis Document. Tucson: University of Arizona.

Huete A, Didan K, Miura T, et al. 2002. Overview of the radiometric and biophysical performance of the MODIS vegetation indices. Remote Sensing of Environment, 83(1-2): 195-213.

Ji L, Peters A. 2003. Assessing vegetation response to drought in the northern Great Plains using vegetation and drought indices. Remote Sensing of Environment, 87(1): 85-89.

Jin H J, Li S X, Cheng G D, et al. 2000. Permafrost and climatic change in China. Global and Planetary Change, 26: 387-404.

Jordan C F, 1969. Deviation of leaf area index from quality of light on the forest floor. Ecology, 50: 663-666.

Karl T R. 1986. The sensitivity of the Palmer Drought Severity Index and Palmer's Z-Index to their calibration coefficients including potential evapotranspiration. Journal of Applied Meteorology, 25: 77-86.

Kogan F, Sullivan J. 1993. Development of global drought-water system using NOAA/AVHRR data. Advances in Space Research, 13(5): 219-222.

Kogan F. 1994. NOAA plays leadership role in developing satellite technology for drought watch. Earth Observation Magazine: 18-21.

Kogan F. 1997. Global drought watch from space. Bulletin of the American Meteorological Society, 78: 621-636.

Li F X, Wang L X, Liu J, et al. 2003. Study on water requirement and the moisture index of spring wheat in irrigated areas of Ningxia. Chinese Journal of Eco-agriculture, 11(4): 108-110.

Li P J, Mi D S. 1983. Distribution of snow cover in China. Journal of Glaciology and Cryopendology, 5(4): 9-17.

Liu M L, Tang X M, Liu J Y, et al. 2001.Research on scaling effect based 
on $1 \mathrm{~km}$ grid cell data. Journal of Remote Sensing, 5(3): 183-190.

Ma Z G, Fu C B. 2006. Some evidence of drying trend over northern China from 1951 to 2004. Chinese Science Bulletin, 51(23): 2913-2925.

McKee T B, Doesken N J, Kleist J. 1993. The relation of drought frequency and duration to time scales. In: Proceedings of the Eighth Conference on Applied Climatology. Boston: American Meteorological Society, 179-184.

McKee T B, Doesken N J, Kleist J. 1995. Drought monitoring with multiple time scales. In: Proceedings of the Ninth Conference on Applied Climatology. Boston: American Meteorological Society, 233-236.

Miller T D. 1999. Growth stages of wheat: identification and understanding improve crop management. Texas Agricultural Extension Service, the Texas A\&M University system, SCS-1999-16. http:// varietytesting.tamu.edu/wheat/docs/mime-5.pdf.

Mkhabela M S, Bullock P, Raj S, et al. 2011. Crop yield forecasting on the Canadian prairies using MODIS NDVI data. Agricultural and Forest Meteorology, 151(3): 385-393.

Nicholson S E, Farrar T J. 1994. The influence of soil type on the relationships between NDVI, rainfall, and soil moisture in semi-arid Botswana. I. NDVI response to rainfall. Remote Sensing of Environment, 50(2): 107-120.

Palmer W C. 1965. Meteorological Drought. US Weather Bureau Research Paper No. 28.

Palmer W C. 1968. Keeping track of crop moisture conditions, nationwide: the new crop moisture index. Weatherwise, 21: 156-161.

Quiring S M. 2009. Developing objective operational definitions for monitoring drought. Journal of Applied Meteorology and Climatology, 48(6): 1217-1229.

Quiring S M, Ganesh S. 2010. Evaluating the utility of the Vegetation Condition Index (VCI) for monitoring meteorological drought in Texas. Agricultural and Forest Meteorology, 150(3): 330-339.

Rouse J W, Hass R H, Schell J A, et al. 1974. Monitoring vegetation systems in the Great Plains with ERTS. In: The Third Earth Resources Technology Satellite-1 Symposium, Greenbelt, MD, 309-317.

Shen J G. 2008. Chinese Meterological Disasters Dictionary: Inner Mongolia volume. Beijing: China Meteorological Press, 8

Shu B R, Liu Y Z, Lu X P, et al. 2008. Application of the theory of energy analysis to the sustainability assessment of cultivated lands: a case study of Nanjing. Journal of Natural Resources, 23(5): 876-885.

Svoboda M. 2000. An introduction to the drought monitor. Drought Network News, 12: 15-20.

Tannehill I R. 1947. Drought: Its Causes and Effects. Princeton: Princeton University Press, 264.

Thornthwaite C W. 1948. An approach toward a rational classification of climate. Geographical Review, 38(1): 55-94.

United Nations Convention to Combat Desertification (UNCCD). 1994. Intergovernmental Negotiating Committee for the Elaboration of an International Convention to Combat Desertification in Those Countries Experiencing Serious Drought and/or Desertification, Particularly in Africa. General Assembly: 5. http://www.unced.int/en/aboutthe-convention/Pages/About-the-Convention.aspx.

Wang J, Price K P, Rich P M. 2001. Spatial patterns of NDVI in response to precipitation and temperature in the central Great Plains. International Journal of Remote Sensing, 22: 3827-3844.

Wang X P, Zhao H Y. 2006. The Climate Resource and Zoning of Forestry, Animal Husbandry and Fishery in Hulunbeier Municipality of Inner Mongolia. Beijing: China Meteorological Press, 111-112, 145-148.

World Meteorological Organization (WMO). 1975. Drought and Agriculture. WMO Note 138, Publ. WMO-392, Geneva, Switzerland, 127.

Zarafshani K, Sharafi L, Azadi H, et al. 2012. Drought vulnerability assessment: the case of wheat farmers in western Iran. Global and Planetary Change, 98-99: 122-130.

Zhang C F, Wang D H, Qiu B J. 1987. Agricultural Phenology Atlas in China. Beijing: Science Press, 26-31, 50-53, 88-90.

Zhang J Q. 2004. Risk assessment of drought disaster in the maize-growing region of Songliao Plain, China. Agriculture, Ecosystems and Environment, 102(2): 133-153.

Zhou H J, Rompaey A V, Wang J A. 2009. Detecting the impact of the 'Grain for Green' program on the mean annual vegetation cover in the Shaanxi province, China using SPOT-VGT NDVI data. Land Use Policy, 26(4): 954-960.

Zipporah M. 2011. Temporal relationships between remotely sensed soil moisture and NDVI over Africa: potential for drought early warning? MSc Thesis. Enschede: University of Twente, 30. 